\title{
Isolation and Charaterization of Bioemulgent from the Fruit Pulp of Prunus insititia
}

\author{
Abhishek Bansal ${ }^{1}$, N.V. Satheesh Madhav ${ }^{2}$ and A.K. Sharma ${ }^{3}$ \\ ${ }^{1}$ Department of Pharmaceutical Sciences, Gurukul Kangari University, Haridwar, Uttarakhand, India \\ ${ }^{2}$ Novel Drug Delivery Research Laboratory, Faculty of Pharmacy, Dehradun Institute of Technology \\ University, Dehradun, Uttarakhand 248009, India \\ ${ }^{3}$ Asmara College of Health Sciences, Eritrea, Africa
}

Received: July 07, 2013; Accepted: November 20, 2014; Published (web): February 09, 2015

\begin{abstract}
The aim of the research work was to isolate biopolymer and to evaluate its emulsifying ability by formulating o/w type of emulsion. The biopolymer was isolated from the fruit pulp of Prunus insititia by treating with water. The aqueous extract was treated with an optimized ratio of dimethyl ketone and kept in refrigeration for 6 hours. The biopolymer was collected by centrifugation, dried and subjected to physicochemical analysis like solubility, $\mathrm{pH}$, colour, viscosity. Eight different emulsions of o/w type were prepared by using liquid paraffin oil and biopolymer in various concentrations ranging from $50 \mathrm{mg}$ to $1 \mathrm{gm}$. The formulated emulsions were subjected for various evaluation parameters like globule size, $\mathrm{pH}$, the effect of freezing and thawing cycle, effect of centrifugation, etc. The results were compared with the standard emulsion which was prepared by using acacia as an emulsifier. The emulsions were not showing any significant stability due to increase in the globule size. The final conclusion can be drawn that the biopolymer as an emulsifier in lower concentration $(50$ and $100 \mathrm{mg}$ ) showed its potential emulsifying property in the formulation FE1 and FE2 with uniform globule size ranging from 12 to $30 \mu \mathrm{m}$ and stable for 3 freezing and thawing cycles.
\end{abstract}

Key words: Bioemulgent, biopolymer, emulsifier, prunus insititia

\section{INTRODUCTION}

Emulsion formulation requires extensive studies in order to understand important parameters to get stable emulsions. Optimizing a process determines the optimal performance. The optimal operating conditions will be applied to emulsifiers, corresponding to the determination of the critical hydrophilic-lipophilic balance of the emulsion. The formulation of an emulsion lies in the fact that the success of such unstable systems can be judged only after a specific time. When stability problems occur, formulation tests may be extended for a very long period. Accelerated testing could be applied to avoid this problem. Stability of emulsion is determined by the average size of the droplets and the viscosity of emulsion. The smaller the viscosity variations and

Correspondence to: Abhishek Bansal

E-mail: abhbansal@gmail.com

Dhaka Univ. J. Pharm. Sci. 14(1): 1-9, 2015 (June) emulsion droplet size, the better the stability of the system. The bio-polymers can be used to replace the existing synthetic polymers used for the preparation of pharmaceutical dosage forms. The synthetic polymers that are used widely in pharmaceutical field are the cellulose derivatives like sodium carboxy methyl cellulose, HPMC, sodium alginate, acacia etc. these polymers being synthetic may lead to adverse reactions in humans. ${ }^{1}$

Biopolymers possess a unique features like its biodegradability, biocompatibility, biosafety and economical and most have originated from the edible sources. Biomaterials from unripe fruit pulp of Artocaropus heterophyllus and Cocos nucifera have been used as bioemulsifiers. ${ }^{2} P$. insititia consists of minerals, carbohydrate, proteins and fats and belongs to the family Rosaceae. Bisoprolol, 1-(4-((2-(1methylethoxy) ethoxy) methy)-phenoxy)-3-((1methylethyl)-amino)-2-propanol, is a synthetic beta 
1-selective (cardio selective) adrenoceptor blocking agent. It can reduce the heart rate and has being used to treat abnormal rapid heart rhythms. It also can reduce the force of contraction of the heart and lower the blood pressure. ${ }^{3}$

In the current study an attempt was made to isolate biopolymer from the fruit pulp of $P$. insititia by a simplified economic technique using a dimethyl ketone. The isolated biomaterial was subjected for its in-built physicochemical properties along with the emulsifying ability. The emulsifying property of the polymer was screened by formulating an emulsion loaded with bisoprolol as a model drug, oil and biomaterial as an emulsifier. The formulated emulsions were screened for its various evaluation parameters and the results were concluded and compared with the standard polymer acacia. The research results revealed that the biomaterial possesses a significant novel emulsifying ability.

\section{MATERIALS AND METHODS}

Prunus insititia was obtained from local markets, Dehradun and identified at Department of Botany, Abhilashi Institute of PG Sciences, Himanchal (Voucher no. HR/2011/ACP/0045). Gum acacia was obtained from CDH laboratory reagent, New Delhi. All other chemicals and reagents were procured from Himgiri Traders, Dehradun and of pharmacopoeal and/or analytical grade(s).

Extraction and isolation of biopolymer. The method adopted in isolation of biomaterial from the fruit pulp of $P$. insititia is the addition of non-solvent to the aqueous solution of fruit pulp. The mixture was kept in the refrigerator over $24 \mathrm{hrs}$ for the complete separation of biopolymer and later it was recovered by centrifugation followed by drying in desiccator for $24 \mathrm{hrs}$. The uniqueness of this method was that the biopolymer was isolated without heating the aqueous solution and concentrating and in the recovery step complete recovery was achieved by placing the mixture in a refrigerator over a period of $24 \mathrm{hrs}^{4-10}$

Physicochemical evaluations of biopolymer. The isolated biopolymer was subjected to analysis for physicochemical properties like solubility, $\mathrm{pH}$, colour, viscosity and surface tension. ${ }^{11-13}$

Determination of viscosity. $1 \% \mathrm{w} / \mathrm{v}$ solution of the biopolymer was prepared and viscosity was measured with a Ostwald viscometer at $25^{\circ} \mathrm{C}$.

Determination of $\mathbf{p H} .1 \% \mathrm{w} / \mathrm{v}$ solution of the biopolymer was prepared and $\mathrm{pH}$ was measured using a pen-type $\mathrm{pH}$ meter at $25^{\circ} \mathrm{C}$.

Determination of surface tension. $1 \% \mathrm{w} / \mathrm{v}$ solution of the biopolymer was prepared and surface tension was measured using stalagmometer at $25^{\circ} \mathrm{C}$ by the drop count method. ${ }^{14}$

Chemical characterization. The extracted biopolymer was tested for chemical characteristics like test for carbohydrates, proteins, alkaloids, mucilage, chlorides and sulphates. ${ }^{15}$

Evaluation of acute toxicity. The biopolymer, which was isolated from the fruit pulp of $P$. insititia was subjected for acute oral toxicity study. The study protocol was approved by the Institutional Animal Ethical Committee (Registration No. 1435/PO/a/11/CPCSEA). The procedure followed was as per OECD 423 guidelines. Two groups of 6 Albino rats, one for test and another for control, were used for the study. The study was performed by administering the biopolymer at $5 \mathrm{~g} / \mathrm{kg}$ body weight to the test group animals. The acute toxicity study was evaluated for 14 days by observing body weight, changes in the skin, corneal reflex, respiratory rate, autonomic symptoms, salivation, diarrhoea, lethargy, sleep, behavioural patterns, and convulsions and compared with the control group animals. ${ }^{16}$

Screening for emulsifying ability. The biopolymer was screened for its emulsifying ability by preparing emulsions using liquid paraffin as oil, biopolymer as an emulsifier, bisoprolol as a model drug and other co-processing agents like preservatives. Eight different emulsions (FE1 to FE8) were formulated by varying proportions of biopolymer by dry gum method. By measuring a specified quantity of mineral oil, biopolymer and water required for preparing the primary emulsion it was calculated based on the ratio of 4:2:0.05 to 10 . 
Initially biopolymer was transferred into the mortar and triturated with the mineral oil for 3 minutes later specified quantity of distilled water required for primary emulsion was incorporate at once and triturated until to form primary emulsion. Finally the emulsion was suitably diluted with distilled water containing preservatives and all formulated emulsions were subjected for various evaluation parameters including their stability studies. ${ }^{1}$

Evaluation of emulsions. The prepared emulsions were subjected for various evaluation parameters like color, homogeneity, consistency, globule size, $\mathrm{pH}$, the effect of freezing and thawing cycle and effect of centrifugation. ${ }^{17-19}$

Globule size determination. The globule size of the prepared emulsion was measured with an optical microscope $(\mathrm{x} 400)$ equipped with a calibrated eyepiece micrometer. The mean diameter was calculated by observing at least 150 globules with the formula: $d m=\sum d_{i} n_{i} / \sum n_{i}$ where $n_{i}$ is the number of globules with diameter $\mathrm{d}_{\mathrm{i}}$.

Centrifugal effect. The emulsions were placed in the centrifuge tubes of centrifuge for $15 \mathrm{~min}$ with $4000 \mathrm{rpm}$. The stability of emulsion ' $\mathrm{S}$ ' was determined by the formula: $\mathrm{S}=\left[\left(\mathrm{V}_{0}-\mathrm{V}\right) / \mathrm{V}_{0}\right] \mathrm{X} 100 \%$.

Where, $S=$ stability of emulsion $\%, \quad \mathrm{~V} 0=$ emulsion volume, which undergoes centrifugation $\mathrm{cm} 3, \mathrm{~V}=$ Volume of the phase given off $\mathrm{cm}^{3}$. No phase separation was observed in any case of formulation, indicating $100 \%$ stability after centrifugation.

Freezing and thawing cycle. The prepared emulsion formulations were subjected to freezing and thawing cycle. For one cycle the first one hour emulsions were kept at room temperature and for second one hour the emulsions were kept in deep freeze. The volume of creaming or phase separation was observed and reported.

Heating and cooling. The prepared emulsions were subjected to heating and cooling cycles. For one cycle, the first one hour emulsions were kept at room temperature and for next one hour, the emulsions were kept in a refrigerator. The volume of creaming or phase separation was observed and reported.
Viscosity. The prepared emulsions were subjected to viscosity measurements at room temperature $\left(25 \pm 0.1{ }^{\circ} \mathrm{C}\right)$ by using Fungi Lab Viscometer and rotated at 12 [min.] and 80 [max.] rpm by using spindle no.61. The corresponding dial reading was noted at each speed.

FTIR of biopolymer. The extracted biopolymer was subjected to FTIR spectroscopy. The sample for the analysis was prepared by solid sampling technique using potassium bromide pellets and recorded with a FTIR 1601 (Shimadzu, Tokyo, Japan) instrument. The scanning range was 500-4000 $\mathrm{cm}^{-1}$.

HPLC of biopolymer. The extracted biopolymer was subjected to HPLC (Acme 9000, Young Lin Instrument, Korea). The flow rate was maintained at $1 \mathrm{ml} / \mathrm{min}$ and the sample was detected at $283 \mathrm{~nm}$.

DSC of biopolymer. The glass transition temperature (TG) and melting temperature (Tm) of the biopolymer was analyzed with a Perkin Elmer, Jade DSC (Temp- $50-250{ }^{\circ} \mathrm{C}$, at the rate of 10 ${ }^{\circ} \mathrm{C} / \mathrm{min}$, nitrogen gas flow rate- $20 \mathrm{ml} / \mathrm{min}$ ).

Drug content uniformity. Drug content in emulsion was measured by spectrophotometer. Bisoprolol concentration in emulsion was measured by dissolving known quantity of emulsion in solvent (methanol) by sonication. After suitable dilution absorbance was measured at $224 \mathrm{~nm}$ with a UV/VIS spectrophotometer (UV-1700 CE, Shimadzu Corporation, Japan).

In vitro drug release study. The in vitro drug release study of bisoprolol from the emulsions was studied through the surface of egg membrane. The egg membrane was clamped between the donor and the receptor chamber of diffusion cell, with a diffusional area of $1.767 \mathrm{~cm}^{2} .1 \mathrm{~g}$ of the emulsion was placed on the membrane surface in the donor compartment which was sealed from the atmosphere with a plastic film, in order to ensure sink conditions during the experiment. The receptor compartment of the cell was filled with $7 \mathrm{ml}$ of phosphate buffer $(\mathrm{pH}$ 7.4). During the study, the solution on the receptor side was kept at $37 \pm 1^{\circ} \mathrm{C}$ and it was stirred 
magnetically at $600 \mathrm{rpm}$. The samples from the receptor compartment were withdrawn at 30,60, 120, 180, 240, 300 and 360 minutes interval and immediately replaced by an equal volume of fresh buffer solution (to keep the diffusion medium constant). The collected samples were analyzed for the bisoprolol assay spectrophotometrically at a wavelength of $224 \mathrm{~nm}$. All release studies were carried out in triplicate.

Accelerated stability studies of emulsions. Accelerated stability studies of emulsions were performed according to ICH guidelines. The prepared formulations were stored in hot air oven at $37 \pm 2{ }^{\circ} \mathrm{C}$, $45 \pm 2{ }^{\circ} \mathrm{C}$ and $60 \pm 2{ }^{\circ} \mathrm{C}$ for a period of 3 months. The samples were analyzed for drug content every two weeks by a UV-Visible spectrophotometer at 224 $\mathrm{nm}$. Stability study was also carried out by measuring the change in $\mathrm{pH}$ of the emulsion at regular interval of time.

\section{RESULTS AND DISCUSSION}

Preparation of emulsions. The formulated eight emulsions were showed uniformity in the globule size ranging from $8-30 \mu \mathrm{m}$ and the emulsions were stable for a period of 4 to 5 cycles when they subjected for freezing and thawing cycle and all were shown there is no sign of separation when the emulsions were subjected for the centrifugation. Oil separation was insignificant up to 15 minutes, whereas in case of standard emulsion showed $40 \%$ of oil was separated during centrifugation in 5 minutes. The emulsions which were prepared by using biopolymer showed significant stability and uniform globule size than compared to the emulsions that are prepared by using acacia as a standard emulsifier. The formula for the preparation of emulsions is given in the table. 1.

Table 1. Preparation of formulated emulsions.

\begin{tabular}{lcccccccc}
\hline Formulation & FE1 & FE2 & FE3 & FE4 & FE5 & FE6 & FE7 & FE8 \\
\hline Drug (mg) & 10 & 10 & 10 & 10 & 10 & 10 & 10 & 10 \\
Oil (ml) & 30 & 30 & 30 & 30 & 30 & 30 & 30 & 30 \\
Biopolymer (mg) & 50 & 100 & 200 & 400 & 600 & 800 & 1000 & - \\
Acacia (gm) & - & - & - & - & - & - & - & 10 \\
Sodium benzoate (\%) & 0.5 & 0.5 & 0.5 & 0.5 & 0.5 & 0.5 & 0.5 & 0.5 \\
Water up to (ml) & 100 & 100 & 100 & 100 & 100 & 100 & 100 & 100 \\
\hline
\end{tabular}

\section{Physicochemical characterization of}

biopolymer. The extracted biopolymer was brown in color and soluble in water and methanol. The $\mathrm{pH}$ of $1.0 \% \mathrm{w} / \mathrm{v}$ solution was $6.9 \pm 0.04$. The viscosity of $1.0 \% \mathrm{w} / \mathrm{v}$ solution was $1.093 \pm 0.01 \mathrm{cps}$ and the surface tension of $1.0 \% \mathrm{w} / \mathrm{v}$ solution was $67.012 \pm$ 0.04 dynes $/ \mathrm{cm}^{2}$. The results of which are given in table 2.

Chemical characterization. The extracted biopolymer was tested for chemical tests for carbohydrates, proteins, mucilage, chlorides and sulfates. ${ }^{11,12}$ The results are shown in Table 3 .
Table 2. Physicochemical characterization of the biopolymer.

\begin{tabular}{ll}
\hline Physicochemical characteristics & Observation \\
\hline $\mathrm{pH}(1.0 \% \mathrm{w} / \mathrm{v}$ solution $)$ & $6.9 \pm 0.04$ \\
Color & Brown \\
Solubility & $\begin{array}{l}\text { Soluble in water, methanol, } \\
\text { dil. Hcl and } 20 \% \mathrm{NaoH}\end{array}$ \\
Viscosity $(1.0 \% \mathrm{w} / \mathrm{v}$ solution $)$ & $1.093 \pm 0.01 \mathrm{cps}$ \\
Surface tension $(1.0 \% \mathrm{w} / \mathrm{v})$ & $67.012 \pm 0.04 \mathrm{dynes} / \mathrm{cm}^{2}$ \\
\hline
\end{tabular}

FTIR of biopolymer. The FTIR spectrum of biopolymer obtained from $P$. insititia showed characteristic peaks at 2934.82, 2363.87, 1731.19, 1638.60, 1419.67, 1260.54, 1078.25, 892.12, 817.85, 778.31 and $668.36 \mathrm{~cm}^{-1}$. The FTIR spectrum of biopolymer obtained from $P$. insititia is shown in figure 1. 
HPLC of biopolymer. The HPLC date of the extracted biopolymer revealed that the polymer showed a sharp peak at $283 \mathrm{~nm}$ with a RT (min) at 3.5 minutes. This characteristic can be used to identify its retention time of the polymer using mobile phase methanol. The graph is shown in figure 2 .

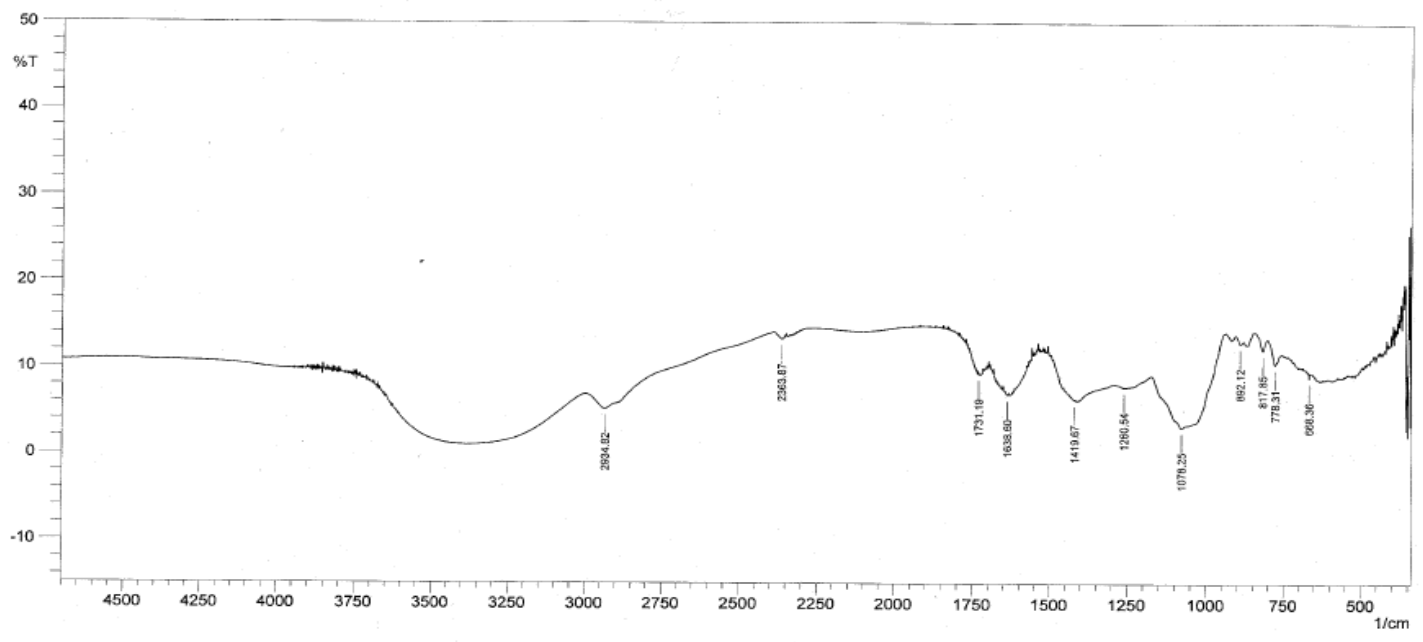

Figure 1. FTIR of biopolymer.

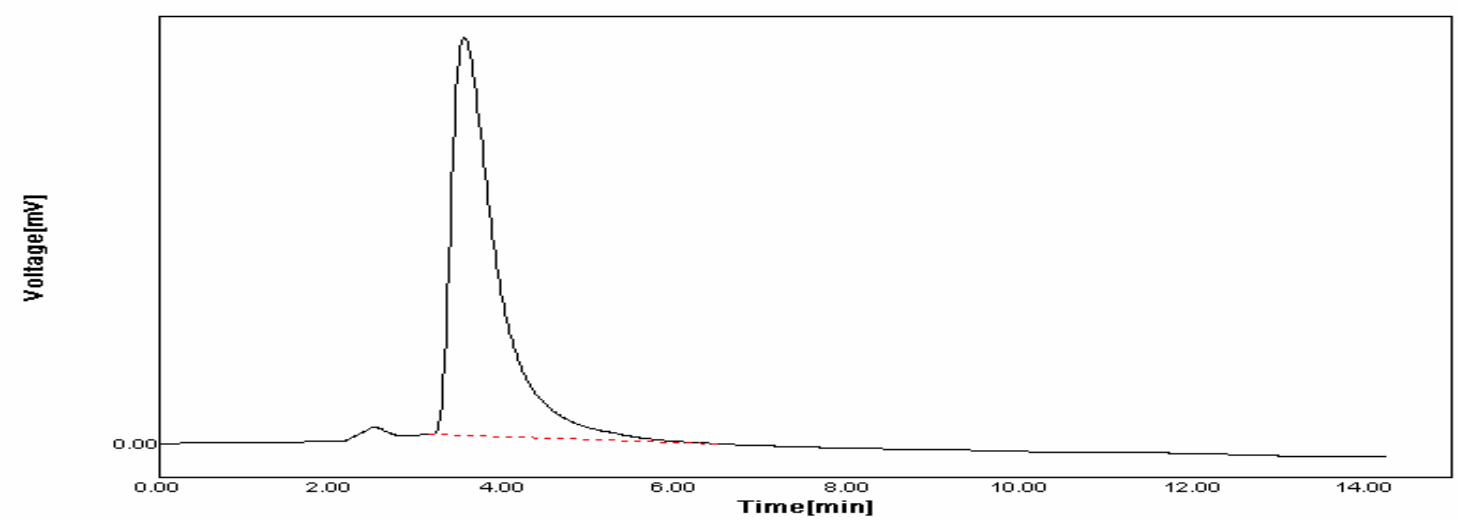

Figure 2. HPLC of biopolymer.

Table 3. Chemical test of biopolymer.

\begin{tabular}{lc}
\hline Tests & Observation \\
\hline Test for carbohydrates & + \\
Test for proteins & + \\
Test for alkaloids & - \\
Test for mucilage & + \\
Test for chlorides & - \\
Test for sulfates & - \\
\hline
\end{tabular}

DSC of biopolymer. The DSC spectra of the extracted biopolymer revealed that the polymer started changing its state at $120.76{ }^{\circ} \mathrm{C}$ and ended at $151.81^{\circ} \mathrm{C}$ and the GTT of the polymer was determined at $137.82^{\circ} \mathrm{C}$ at this temperature the behavior of the polymer started changing at $137.82^{\circ} \mathrm{C}$ from glassy state to rubbery state at this temperature the polymer undergoes enthalpy of relaxation which appears as a positive deviation from the DSC base line that results in an increase in the specific heat above $\mathrm{Tg} .{ }^{20}$ The DSC spectrum is shown in figure 3 .

Evaluation of formulated emulsion. The prepared emulsions were white in color, viscous creamy preparations with a smooth and homogeneous appearance. The results of various evaluation 
parameters are shown in Table 4. The viscosity and drug content of the formulated emulsions were also determined the results are shown in figures 4 and 5, respectively.

Effect of centrifugation (at $4000 \mathrm{rpm}$ ). All formulations were found to be stable for 60 minutes.
Effect of freezing and thawing cycle $(1$ cycle $=$ 15 mins). All formulations were stable for 3 cycles.

Effect of heating and cooling cycle $(1$ cycle $=$ 15 mins). All formulations were stable for 4 cycles.

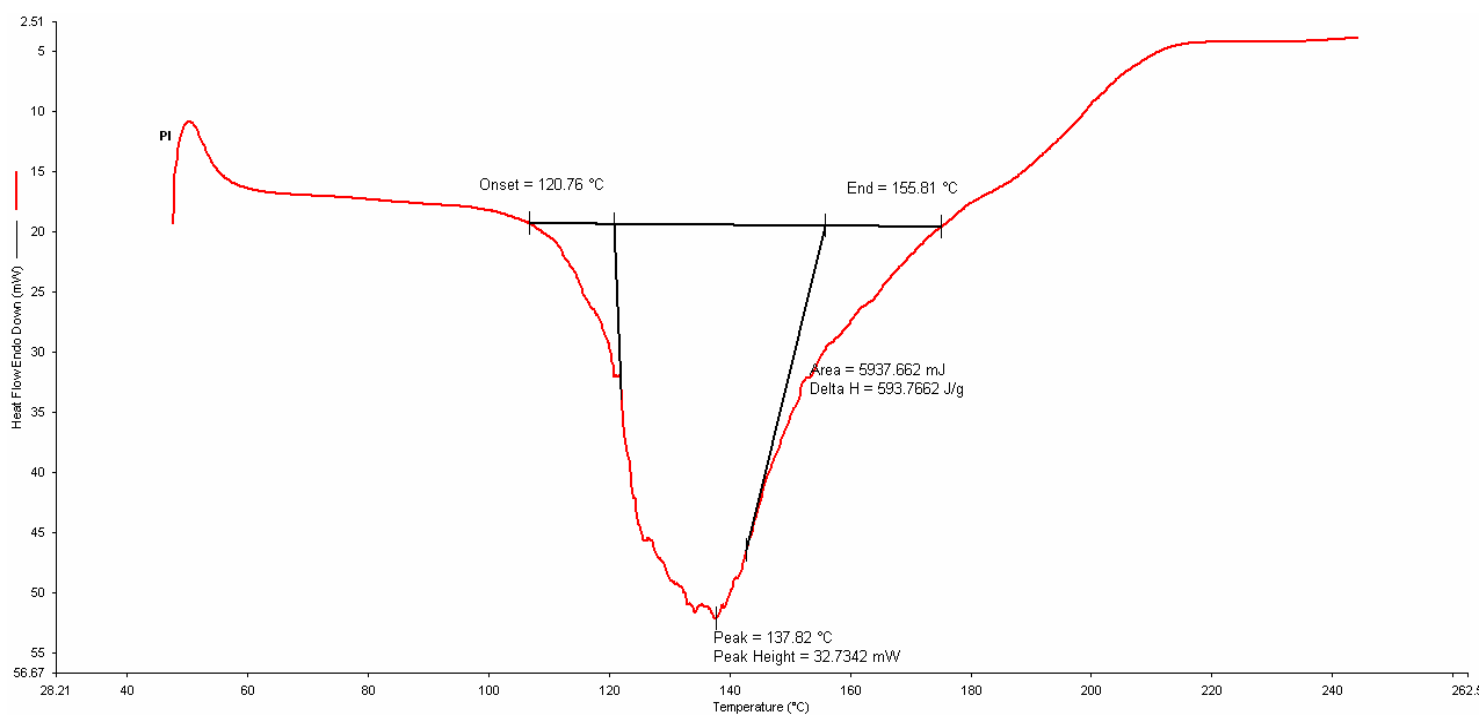

Figure 3. DSC of biopolymer.

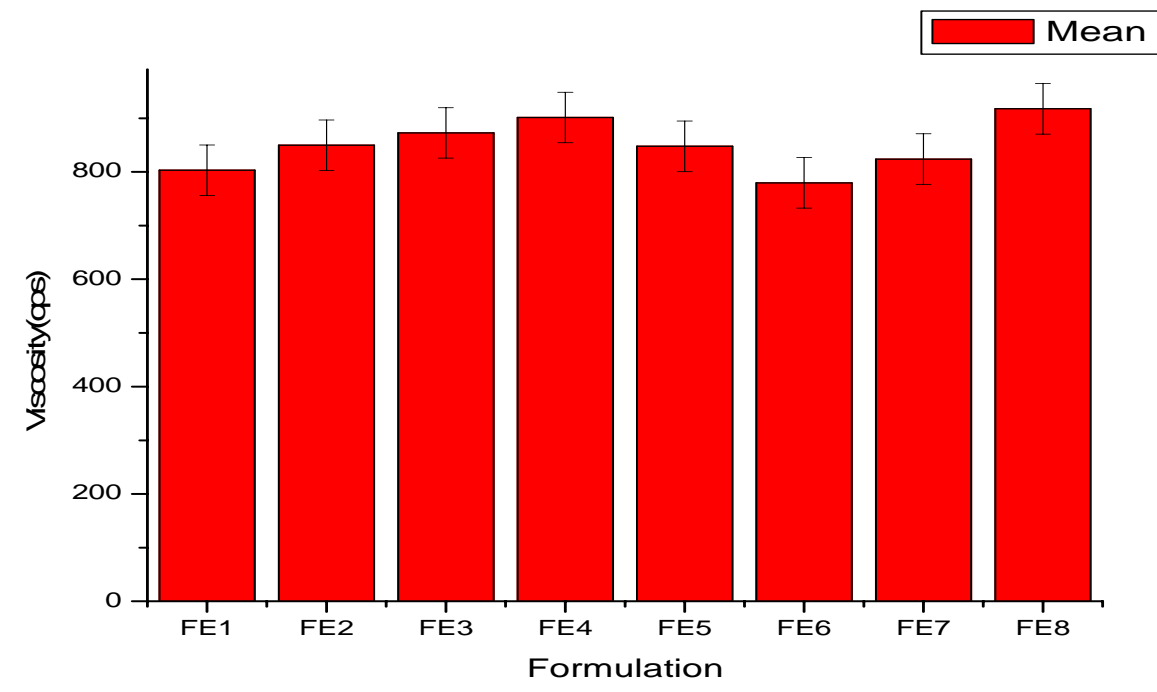

Figure 4. Viscosity of prepared emulsions. 


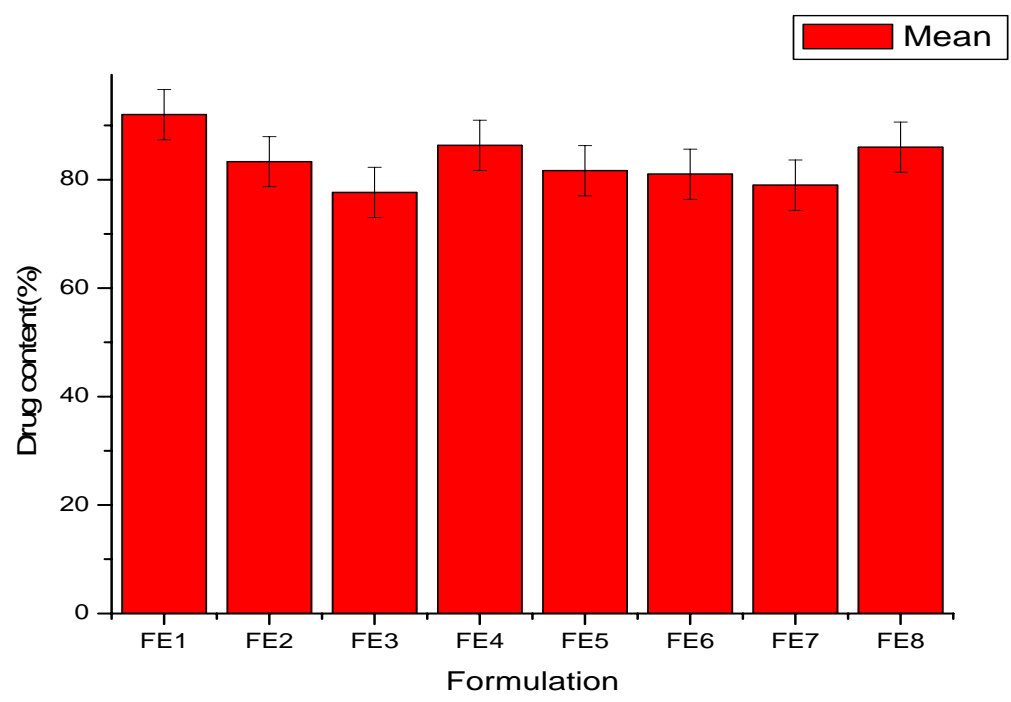

Figure 5. Drug content studies.

Acute toxicity studies. The limit dose of $5 \mathrm{~g} / \mathrm{kg}$ did not cause any mortality or signs of acute toxicity in the rats tested during the observation period. This indicates that the biopolymer is relatively safe when administered orally in rats. The acute toxicity study revealed that there is no any sign of toxic reactions and behavioral changes, observe in experimental animals as the polymer is isolated from the fruit pulp of $P$. insititia which is edible and generally recognized as a safe and comprises of mainly carbohydrates, proteins, fats and minerals having edible value.

Table 4. Physical evaluation of formulated emulsions.

\begin{tabular}{llc}
\hline Formulation & $\mathrm{pH}$ & Globule size $(\mu \mathrm{m})$ \\
\hline FE1 & $8.4 \pm 0.05$ & $8-11$ \\
FE2 & $8.4 \pm 0.05$ & $12-18$ \\
FE3 & $7.2 \pm 0.11$ & $9-13$ \\
FE4 & $7.5 \pm 0.11$ & $10-18$ \\
FE5 & $8.1 \pm 0.1$ & $12-23$ \\
FE6 & $7.4 \pm 0.1$ & $17-28$ \\
FE7 & $8.3 \pm 0.11$ & $12-25$ \\
FE8 & $8.4 \pm 0.11$ & $10-30$ \\
\hline
\end{tabular}

In vitro drug release study. All the formulated emulsions were subjected to in vitro drug release study. FE1 and FE2 showed a good release profile after $8 \mathrm{hrs}$. The in vitro drug release profile of all the formulations is shown in figure 6 .
The in-built property of the polymer was screened by formulating emulsions using liquid paraffin oil, water and bisoprolol as a model drug and along with biopolymer as a bioemulgent. Our experimental results revealed that the formulated emulsions, FE1 and FE2 showed significant stability along with the promising in vitro release profile with a pattern of zero order and the drug release was extended for a period of $8 \mathrm{hrs}$. The proposed mechanism of the biomaterial for making stable emulsion between oil and water is due to forming a thin film coat over the dispersed phase globules and assist to reduce the interfacial tension between two phases and the polymer potentiality was compared with the emulsion that was prepared by acacia as an emulsifier in the ratio of 1:10. In comparison with standard, the biopolymer displayed significant stability in lower concentration 1:0.5 and 1:1 whereas the standard polymer displayed it's at 1:10 ratio. This result confirms that at very low concentration it posses potential emulsifying ability property for stabilizing the drug loaded biphasic system. 


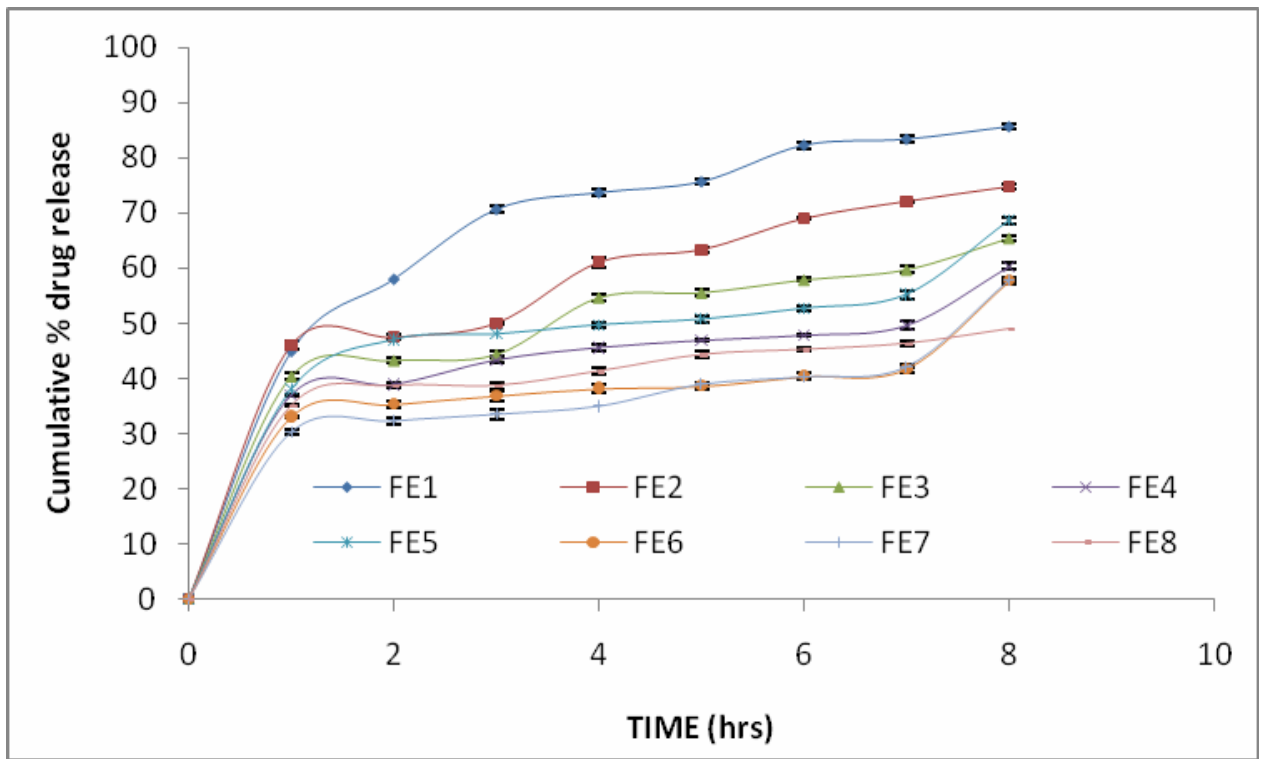

Figure 6. In vitro drug release.

Table 5. Accelerated stability study of optimized emulsion formulation FE1 and FE2.

\begin{tabular}{|c|c|c|c|c|c|c|}
\hline \multirow{2}{*}{$\begin{array}{l}\text { Storage } \\
\text { temp. }{ }^{\circ} \mathrm{C} \\
\end{array}$} & \multicolumn{3}{|c|}{ Period of studies in months (FE1) } & \multicolumn{3}{|c|}{ Period of studies in months (FE2) } \\
\hline & 1 month & 2 months & 3 months & 1 month & 2 months & 3 months \\
\hline $37 \pm 2$ & $91.2 \pm 1.10$ & $90.3 \pm 0.48$ & $90.2 \pm 0.61$ & $82.1 \pm 0.52$ & $82.02 \pm 0.56$ & $83.15 \pm 0.53$ \\
\hline $45 \pm 2$ & $92.0 \pm 0.29$ & $92.11 \pm 0.49$ & $94.06 \pm 0.09$ & $83.21 \pm 1.00$ & $81.05 \pm 0.60$ & $82.24 \pm 0.41$ \\
\hline $60 \pm 2$ & $93.1 \pm 0.52$ & $95.03 \pm 1.37$ & $93.05 \pm 0.41$ & $81.12 \pm 1.15$ & $83.20 \pm 0.56$ & $84.11 \pm 0.49$ \\
\hline $\mathrm{pH}$ & $8.4 \pm 0.05$ & $8.2 \pm 0.1$ & $8.3 \pm 0.1$ & $7.4 \pm 0.11$ & $7.8 \pm 0.05$ & $8.1 \pm 0.1$ \\
\hline
\end{tabular}

Accelerated stability studies of emulsions. The accelerated stability studies were performed according to ICH guidelines for 3 months and the results were found to be stable in varying temperature as shown in table 5 .

\section{CONCLUSION}

This biopolymer may serve as a potential bioemulgent for preparing various drug loaded formulations or drug loaded colloidal dosage forms. The biopolymer in lower concentration showed potential emulsifying property in the formulations FE1 and FE2 containing 50 and $100 \mathrm{mg}$ along with uniform globule size ranging from 12 to $30 \mu \mathrm{m}$ and stable for 3 freezing and thawing cycles. These emulsions were very significantly stable in comparison to the standard emulsion formulated with acacia.

\section{Conflicts of interest}

All authors have none to declare.

\section{REFERENCES}

1. Madhav, S. and Tangri, P. 2011. Formulation of escitalopram emulsion using a novel bio- emulsifier from unriped fruit pulp of Artocarpus heterophyllus. J. App. Pharma. Sci. 1, 194-196.

2. Madhav, N.V.S. and Shankar, M.S.U. 2008. A novel biopolymeric smart stabilizer from Cocos nucifera meat kernel and its pharmaceutical applications. Indian Patent Application.

3. Chang, H. 2012. Simultaneous determination of amlodipine and bisoprolol in rat plasma by a liquid chromatography/tandem mass spectrometry method and its application in pharmacokinetic study. J. Pharmaceut. Bio. Ana. 71, 104- 110.

4. Bansal, A., Madhav, S. and Sharma, A.K. 2012. Isolation and characterization of biomaterial obtained from Citrus maxima juice. Inventi Rapid: Novel Excipients. 3, 1-3. 
5. Sumathi, S. and Ray, A.R. 2002. Release behavior of drugs from tamarind seed polysaccharide tablets. J. Pharm. Pharmaceut. Sci. 5, 12-18.

6. Sharma, S., Bharadwaj, S. and Gupta, G.D. 2008. Fast dissolving tablets of promethazine theoclate by using naturally super disintegrants. Res. J. Pharm. Tech. 1, 218224.

7. Deveswaran, R., Bharath, S., Sharon, F. and Basavaraj, B.V. 2009. Studies on the disintegrant properties of mucilage and seed powder of Plantago ovate. Int. J. Chem. Tech. Res. 1, 621-626.

8. Patel Dhara, B. and Patel Madhabhai, M. 2009. Natural excipients in controlled drug delivery systems. J. Pharm. Res. 2, 900-907.

9. Martin, E., Phyllis, N., Christina, I. and Joseph, F. 2009. Isolation, characterization and formulation properties of a new plant gum obtained from Cissus refescence. Indian J. G. Pharm. 3, 16-23.

10. Rao, P.S. 1946. Extraction and purification of tamarind seed polysaccharide. J. Sci. Indian Res. 4, 705.

11. Ghule, B.V., Darwhekar, G.D., Jain, D.K. and Yeole, P.G. 2006. Evaluation of binding properties of Eulophia campestris wall mucilage. Indian J. Pharm. Sci. 68, 566-569.

12. Martin, A. 1991. Physical Pharmacy, $4^{\text {th }}$ ed., Lippincott Williams \& Wilkins, Maryland USA, pp. 423-430.
13. Radhakrishnan, S. and Arof, A.K. 1998. Polymeric materials, Narosa publishing house, London, pp. 46-48.

14. Martin, A. 2001. Physical Chemical Principles in the Pharmaceutical Sciences, $3^{\text {rd }}$ ed., Varghese Publishing House, Bombay, pp. 446-87.

15. Ahad, H.A. and Sreeramulu, J. 2011. Isolation and physicochemical characterization of Ficus reticulate fruit mucilage. Int. J. Green Pharm. 5, 131-134.

16. Madhav, Satheesh, N.V., Shankar, and Uma, M.S. 2011. A novel smart mucoadhesive biomaterial from Lallimantia royalena seed coat. Science Asia 37, 69-71.

17. Madhav, S. and Tangri, P. 2011. Formulation and evaluation of zidovudine bio-micro dwarfs using a novel bio-muco resident from Artocarpus heterophyllus. Int. J. Pharm. Tech. Res. 3, 169-174.

18. Aulton, M.E. 1988. Pharmaceutics- The science of dosage forms design. $2^{\text {nd }}$ ed., Churchill Livingstone London, p. 600.

19. Subramanyam, C.V.S. 2004. Micromeritics. Textbook of Physical Pharmaceutics. $2^{\text {nd }}$ ed., Vallabh Prakashan, Delhi.

20. Kumar, R., Patil, S.R., Mahesh, S.P. and Mahalaxmi, R. 2010. Isolation and evaluation of the emulsifying properties of tamarind seed polysaccharide on castor oil emulsion. Der Pharmacia Lett. 2, 518-527. 